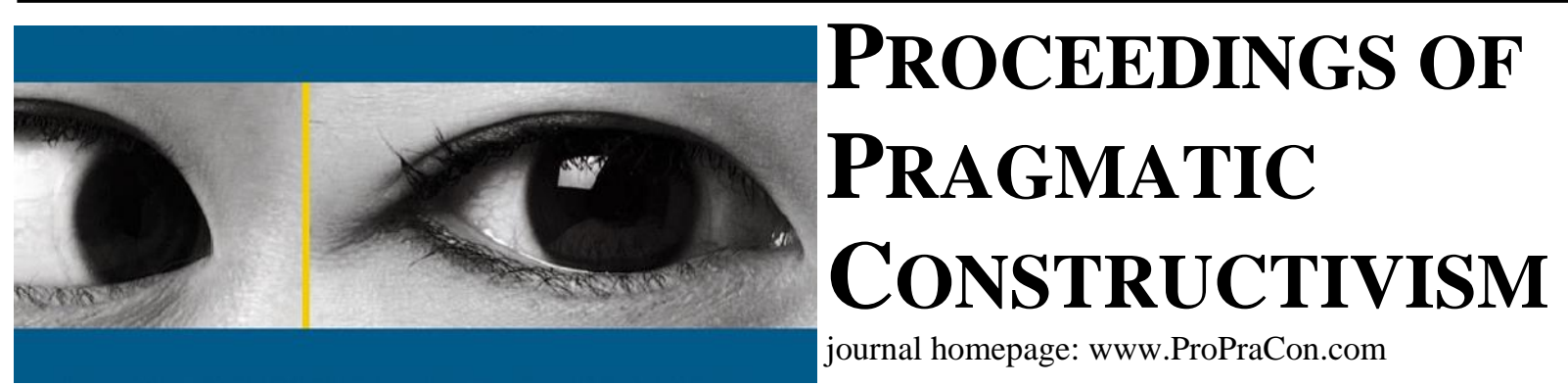

\title{
Future business models of the library - An actor-based case study at Aarhus Urban Mediaspace
}

\author{
Michael Elkjær \\ Research Assistant \\ Aarhus University; School of Business and Social Sciences; Department of Economics and Business \\ Fuglesangs Allé 4; 8210 Aarhus V; Denmark; MJ90157@post.au.dk

\section{Henriette Haugaard} \\ Research Assistant \\ Aarhus University; School of Business and Social Sciences; Department of Economics and Business \\ Fuglesangs Allé 4; 8210 Aarhus V; Denmark; HN89739@post.au.dk \\ Jonas Råbjerg \\ Research Assistant \\ Aarhus University; School of Business and Social Sciences; Department of Economics and Business \\ Fuglesangs Allé 4; 8210 Aarhus V; Denmark; JN90904@post.au.dk

\section{Benjamin Trads \\ Research Assistant} \\ Aarhus University; School of Business and Social Sciences; Department of Economics and Business \\ Fuglesangs Allé 4; 8210 Aarhus V; Denmark; BT90903@post.au.dk
}

\begin{abstract}
Given the changes in the environment, customer demands, and alternative media portals, public libraries are starting to rethink their business models. The purpose of this study is to investigate how business models for public libraries can look in the future. Using pragmatic constructivism as a paradigm, this paper investigates the research question through a case study of the Urban Media space Aarhus (Aarhus Library) with additional comparable data from Aarhus State Library. The empirical data has been collected through interviews with the administrative director of the citizen service center and libraries and with the area director from Aarhus State Library. According to the six types of business models by Henry Chesbrough, Aarhus Library lies between type 5 and 6, which is a company with a quit open business model that has close connections to both partnerships and customers.

The study of these libraries implies that different elements need to be taken into account when defining a business model for public libraries. These elements are customer integration, innovation, and broad collaboration in order to satisfy the diverse customers' demands. We suggest that future libraries have to be well adapted to changes and be quick at picking up new ideas both from customers and partners and other actors in society in order to cope with the ever changing environment.
\end{abstract}

Keywords: Pragmatic constructivism; business model innovation; library. 


\section{Introduction}

Throughout the past few years, libraries have faced severe challenges. Cut downs have led to closings of many libraries (www.b.dk). Technology has evolved, and the environment has changed. These changes have led to higher requirements and expectations of how easy actors can obtain the information and services they need. Because of that, actors do not use the libraries to the same extend and in the same way they did previously. The prevalent substitute actors have turned to instead of the traditional libraries is the internet. According to Chad and Miller (2005), a major strength online substitutes like Google and Amazon etc. have, which the physical libraries do not have, is full accessibility. The fact that the online portals are not limited by opening hours, location, or physical buildings means that they have better chances of meeting the expectations and requirements of the modern world. Despite the internet being an apparent threat to the libraries, it is by law not a competitor, since the public libraries' main purpose is to promote information, education, and culture to the public (Bibliotekstyrelsen chap 1, §1). However, the physical libraries must deal with the challenge of technology and try to turn progress into something that works in their favor if they want to maintain the same right to exist as they have had thus far.

Given these circumstances, a question of how to define the optimal business model of existing as well as new libraries arises. A generic question for public libraries is "how exactly do we get actors to come here?” An obvious answer to that question is to make sure the services libraries can provide meet the expectations of the modern world. But the solution is more complex than that. Since the physical libraries must deal with the limited accessibility, they have to beat the substitutes like online platforms on other fields. This specific challenge requires innovative thinking and creativity from the libraries.

This research paper will investigate what libraries need to do and what service they should offer in the future. It will aim at generating a business model for future libraries. We pose the research question 'How should business models for public libraries be designed in the future?' In order to answer that, a case study of Aarhus Library has been conducted and compared to the state library in Aarhus. These libraries are well suited for a case study like this given that they are both required to have a progressive mind-set in regards to their business model and overall direction.

Although they do this to different degrees, we find that both libraries use modernized business models, compared to traditional libraries. Specifically, there has been a shift in the focus from books to users. This tendency results in new or moderated business models containing factors directed at user satisfaction regarding products and services. This direction has to be balanced with the responsibilities the libraries are expected to fulfil.

The literature that has been the foundation for the theory is retrieved by the search on electronic databases sought at AU library and the Danish authority-list. The search has been within management accounting research and library information science. This is important because business modeling can have different meanings in relation to the research theme. The basic keywords of the search were surrounded by words like: open business models and business modeling in libraries.

We approach this case study from a pragmatic constructivist perspective. This approach assumes knowledge creation, as being the relationship between the subjects and the investigated object. There is not a single truth, but different perspectives on the same object and it depends on the chosen theories and methods. The view has been inspired by the social constructivist view where observation and knowledge is obtained through social relations (Jakobsen et al., 2011). But pragmatic constructivism does not have the uncritical approach social constructivism does. As Carsten Rønn puts it, it depends upon what part of the elephant you are holding on to, but in order to get close to objective truth, you need to see the whole elephant (Rønn 2006).

As for this paper, it is not the intention to find a definite truth. We rather cover certain aspects of how a business model of a library could look like, based upon the perspective that the chosen theory holds. The theory and methods used have a big influence on the results, and these could have a different outcome if other theories were used. The pragmatic approach is applied through the interrelated work between the investigators, the selected framework, and the library, which will construct a part of the truth, related to how the business model at a future library could look. The perspective of the paper will be the open business model framework, including customer-integration. The method is a case study of a relevant library. Both the theory and method will be elaborated further on.

\section{Conceptual background}

The following section will describe the concept open business model and the framework for this. Thereafter the principle customer integration will be explained, and at last a small presentation of the concept innovation. 


\subsection{Open Business Models}

There is no consensus on how to define a business model neither in the business world nor in the academic. Although, over the last 20 years there has been an increase in interest in the subject (George \& Bock, 2010). It is precisely the lack of consensus which has been an obstacle for a more systematic approach to better understanding of the business models and thus understanding what a good business model must include (Morris et al., 2005). This paper will focus on the definition of an open business model presented by Henry Chesbrough. Originally this concept was developed based on production companies, but we have chosen to generalize this model to service companies. The discussion part will take this matter into account.

The open business model is aimed at creating value by working with external partners. It works on the principle of open innovation, where knowledge is shared with external partners - it is a knowledge that goes both ways. The benefit is that you can take advantage of knowledge from outside the organization. Knowledge creation thus depends not only on its own R\&D. At the same time, you can also share your own (redundant) technology and knowledge with external parties and profit from them (e.g. via joint ventures) (Chesbrough, 2007).

Now that open innovation is introduced, it is time to present the business model framework. The framework is divided into six sequential types, from the simple and less valuable to the more advanced and highly valuable. Chesbrough sorts out the companies and potential business models according to the stages of development they belong to. The types are described as follows:

Type 1 - The company has an undifferentiated business model. The majority of companies today lack specific processes to protect their business model. A company that uses an undifferentiated model and competes on price and availability as well as customer buying behavior is based on these criteria. Companies of this type may, for example, be hairdressers and restaurants.

Type 2 - The company has a variation in its business model. Companies operating with a type 2 business model have, to some extent, differentiated their product or service. Companies of this type include other customers than those who buy based on price and availability. The company is therefore able to act in a differentiated and less congested market than companies belonging to Type 1 . A Type 2 company may not have the necessary resources to invest in innovation and maintain its differentiated position. This may, for example, be new technology companies started from a new successful first product who are unable to develop new popular products.

Type 3 - The company develops a segmented business model. The company is now able to simultaneously compete in various customer segments. A larger share of the market is being served, and a larger profit share of the market will be earned. The price-sensitive segment is the basis for a high volume as well as low cost production, and the customers of their other segments provide the company with a high profit margin. Other niches can now be operated, creating a greater presence in the distribution channels. The business model of the company is more profitable and enables them to think long-term in relation to products and technology. The company is still vulnerable to major shifts in the market and technological developments within the current innovation and business activities.

Type 4 - The company has an externally conscious business model. In this model, the company has opened up to external developments in technology and ideas. In cooperation with external partners, the company is preparing to identify external projects that can meet some of the needs that the technological change brings with it. This reduces product and service launch time as well as the time it takes to bring a product to market. It also means a sharing of the risks of this with external parties. Information and planning will now be regularly shared with suppliers and customers, which enables the company to work more systematically in the use of innovative ideas from suppliers and customers. They can also plan their own activities according to the innovative activities of the company. Companies that make it a practice to share real-time information with their suppliers are examples of a type 4 company.

Type 5 - The company integrates innovation processes with its business model. The business model is now playing an integrative role in the whole company. There is reciprocal institutional access to the innovation process in the company, between it and the suppliers and customers. Suppliers and customers share their forward planning with the company, which offers greater visibility and insight into future customer requirements. In this stage start-up companies experiment with the business model itself. They try to understand the supply chain back to the raw materials and identify major technological changes and opportunities to reduce costs. They begin to experiment with alternative distribution channels and business models and invest significant resources in finding unmet needs and market opportunities.

Type 6 - The company's business model is an adaptable platform. A type 6 business model is an even more open and adaptive model than types 4 and 5, and it requires more involvement in the testing of different business models. The test can be done in different ways. Some companies invest venture capital in small start-ups to explore alternative 
business models, others use joint ventures to commercialize technologies outside their own existing business model, while some have departments of the company dedicated to continual testing. This type of company builds a business partnership with their key customers and suppliers. The suppliers' business model is now integrated into the company's planning activities, and the company has also integrated its business model in the business model of key customers (Chesbrough, 2007).

By identifying the type of stage a company is located at, and then looking at the different characteristics at the subsequent development stages, The Business Model Framework, according to Chesbrough, is used to assess the company's current business model and provide some general guidelines on how the company can develop its business model in a forward-looking manner.

\subsection{Customer-integration}

As mentioned, open business modeling is the involvement of external players in the development of the business model of a company. All companies exist and rely on customers, and that is why the opinion of the customers is an important part when developing a business model. There are two determinants in customer participation. The company can either involve the customers in a proactive way, where the company asks customers what they think of their products/services, or if the customers are interested in certain initiatives the company has not thought of. The customers can also involve themselves without being solicited. The trigger for this action can be a problem with a specific service or product. In this case, the customer simply establishes contact with the customer service department. Yet, it could also be whole new ideas that should be investigated further by the company. These could lead to new products or services. The company should treat the feedback from customers as a resource (Plé et al, 2010). The integration of customer participation in the business model framework is placed among the tasks that have been outsourced to companies that can benefit from the mutual companionship. All of these open business model initiatives reduce the overall costs.

\subsection{Innovation}

It is important to distinguish between innovation and invention. Invention as such is not innovative, it is only when invention becomes a saleable product that it is innovation. Until then it is just a technical idea or research result, and as such it carries no intrinsic value. One of the first studies of innovation was made by the economist Joseph Schumpeter (1883-1950). Schumpeter's study outlined five types of innovation (Schumpeter, 1943): new products, new methods of production, new sources of supply, exploration of new markets, and new ways to manage the business (CasadesusMasanell \& Zhu, 2012). This definition is still widely used and referred to by researchers when the concept of innovation is discussed and also in studies on business model innovation (e.g., Casadesus-Masanell \& Zhu, 2012; Chesbrough 2007). Innovation includes all innovations in both internal and external conditions.

\section{Methodology}

\subsection{Case study method}

We opted to make a case study of Aarhus Library, also referred to as Dokk1, and compare that with another library, Aarhus State Library. The research method 'case study' is concluded relevant based on guidelines from Yin (2014), and it enables us to investigate the potential changes in business models for libraries. Single-company case studies with little interview material are an accepted method in contemporary research on business models (examples are Dalby et al., 2014; Haubro et al., 2015; Larsen et al., 2014; Lueg et al., 2014, 2013a,b; Malmmose et al., 2014; Sosna et al., 2010).

\subsection{Data collection}

Data is collected primarily through expert interviews but also through publicly available sources from Aarhus Library and websites. The interviews are semi-structured in order to let the interviewees talk and explain without leading them in any direction. The first interview was conducted with the administrative director of the citizen service center and libraries. He was chosen because he is the municipality's representative on the new library project in Aarhus. This interview took place in the respondent's office and lasted for one hour and 10 minutes. A second interview with the area director from the state library in Aarhus was conducted for comparison. This interview also took place in the respondent's office and lasted for 45 minutes. This approach was taken because of the assumption that these two libraries are quite different but still have values in common. The last part of our data is found on the internet and publicly available sources. We evaluate all the data found online to make sure it is reliable 


\section{Findings}

The purpose of this section is to display the findings from the conducted interviews. The categories are created based on the interviews. Each category is a part of explaining the business model of Aarhus Library. Through a thorough analysis relevant quotes have been extracted. These support each category. The quotes are translated from Danish, causing minor ambiguities with no impact on their meaning. The categories are created from a combination of the conceptual background of the paper and the interviews.

\subsection{Dokk 1}

The new library in Aarhus Dokk 1 (Urban Mediaspace Aarhus) is to be completed at the end of 2015. Before looking at their business model, it is important to outline some of the basic facts for Dokk 1 . This will be done in three sections; first looking at the target group, second the competition, and lastly the economy. The facts are collected in the interview with respondent 1 , the head of Aarhus Library, and from the Dokk 1 website.

\subsubsection{Topoi: the different target groups}

The library in Aarhus is a public library. This means that, in principle, it is required to offer its service to all citizens in Aarhus. However, a concept is implemented called personas. In it 10 different personas represent different types of actors with different topoi, e.g., immigrant parents, elderly and so on. This is not an initiative to segment who to make offers to, but an attempt to create diverse offers. It outlines how to communicate to the different actors in the municipality. The target group is described by respondent 1 :

"In principle, we are legislatively committed to all citizens. In principle, there must be offers available to everyone."

This is also implemented in the vision statement for Dokk 1:

"Dokk1 must be a flexible and dynamic haven for all who desire knowledge, inspiration, and personal growth. An open and accessible learning environment that promotes democracy and community”

\subsubsection{Possibilities: competition and alternatives for actors}

Without a specific target group, it is hard to have any specific competitors. This is also said by respondent 1 :

“... We actually see it not so much as a competition. For us ... we want people to read. And we are pretty much indifferent to whether they use Mofibo or go down to the bookstore and buy it."

So according to respondent 1 Dokk1 does not have any competitors. However, even if respondent 1 claimed that Dokk1 does not have any competitors, respondent 2 said that they have some competition in their target group, the 18-27 year old students in Aarhus. So they have some competitors, rooted in the different topoi of the target groups as well as alternative possibilities actors can use on Mofibo. Respondent 2 said about their competitors:

“...Yes so we compete with all things, that is, Netflix, wimp, play, spotify, mofibo, all media houses who make their own digital newspapers. In the past it was indeed such that the physical library had the monopoly on library activity.”

Also you can make the argument, that if you do not have any competitors, why then change your business model and invest 2 billion in a new library.

\subsubsection{Facts: the economy}

The building of Dokk 1 is budgeted to cost about 2 billion Danish kroner. This is funded by Aarhus municipality as well as Real-dania who has sponsored 661 million Danish kroner to the project. But this is only to the Dokk 1 project, because as respondent 1 said:

“...in 2004 we received, Bill and Melinda Gates, Gates Foundation awards access to Learning Award. At half a million dollars ...”

This was for their work in making the library as innovative as possible. The daily work is paid by Aarhus municipality. However as respondent 1 comments: 
"The public sector cuts to the core, staff wise. So at the main library we have only approximately $40 \%$ of the staff we had 20 years ago."

This has of course affected the way the business model for the library has come to be. The business model has been forcibly changed by public policy to allow continuing their business. Besides these general conditions we found another important factor to have in mind when discussing terms and conditions for a library. It is basically the physical placement of the building in which you have the library or more services. The importance of this factor is, among other, exemplified in the fact that the state library, which is located at the university, does not have nearly as many visitors in July when the university is closed. The new public library in Aarhus is located in an area down by the harbor only recently developed for construction. Whether this new area will attract many actors and activities is yet to be determined. Respondent 2 believes that the success of the new public library will depend on the successful development of the harbor area as a whole. This illustrates how a service institution, like a library, is not always a complete master of its own rate of success, but can be influenced a whole lot by its surroundings.

\subsection{The innovative aspect of the business model: letting actors construct causality}

In aspiration of matching the changes in trends and demands of society, organizations, and thereby libraries, have to incorporate innovative elements in their business model. The foundation for innovative thinking, behavior, and execution is internal and lies within the ability of the actors in the organization to be flexible. The necessary level of flexibility in the staff might not be part of the culture prior to the change in the business model. According to the Director of Citizens Services and Libraries in Aarhus, it is the management's task to make organizational considerations on how to make the staff receptive and open to new opportunities. These considerations are of great importance since innovative thinking plays a major role in the development of the new public library in Aarhus, the "Urban Mediaspace Aarhus”. In this new media space the physical library is placed together with various citizen services. This new space is referred to as a mash-up library. Basically, the new building will contain two different kinds of services. It will contain the public services such as the library, citizen service, passport issuing, and temporary public events. It will also provide space and opportunities for the civil society to use it for various union events and voluntary arrangements like local historical archives, homework cafés etc. The overall intention seems to be a more active approach to satisfying the visitors. In contrast to a traditional library that just presents facts (books) and does not communicate with the visitors, Dokk1 communicates its possibilities, and offers thereby more potential value creation. This increased focus on the service of the customers is in line with Henry Chesbrough's (2011) thoughts. He states that the importance of service is too often underrated and that it is important to know that different customers experience the same service in different ways. In line with that acknowledgement of diversity, the public library in Aarhus internally uses a method of creating so called user-journeys. The idea is to take different segments of the typical users and make each of their journeys through the building as fulfilling and utility rewarding as possible. To make sure the journey is beneficial for the users, the management has a mental model consisting of four rooms. Even though the model is a mental model, it aims to reflect what the physical rooms in the media space should offer. The 4-room-model, which represents the requirements from the law of civic education, consists of the inspiration space, the learning space, the meeting space, and the performative space. Actors will be presented with the opportunities to experience, discover, participate, and create. This change in the business model can be described as rather large. A change this radical can be of high risk, and the probability of getting it all right can be low (Pateli \& Giaglis 2005).

As opposed to that, the State Library in Aarhus has a different strategic approach. According to the director, the development of their strategy has not consisted of radical changes but has been more incremental. Since 80 percent of their users are university students, they have more so adjusted to the demands of these students than trying to increase the number of visitors from all segments. Respondent 2 reveals that even though a digitalization of the media is happening, their strategy is also to attract actors to the library by making attractive rooms and create buzzing activity in the building. To achieve this, among other initiatives, plenty of study areas, lounges and plans of a coffee bar have been made. This strategic choice was made 7 years ago instead of the alternative way where it was completely fine if users stayed at home and used the library as an online portal of access to the desired media.

The innovation aspects described this far have all been centered on internal processes. Contrary, innovation in cooperation with the external environment is of no less significance. This is the open innovation (Chesbrough 2011). This concept is about how organizations can use external ideas and knowledge to their own advantage. Innovation is important but at the same time dangerous for service organizations to invest a lot of resources in. As shown, despite two different libraries standing in different situations, the topoi behind their business models and innovative choices head in a somewhat similar direction. This difficulty in protecting service innovations and making sure that competitors do not copy them is a known barrier to innovation management (Oke 2004). The director of Citizens Services and Libraries in Aarhus explains how they are not reluctant when it comes to copying good ideas from other service organizations. This 
rather rough environment for public organizations is reflected in the way they think, do business, and make strategic choices. As a result, private sector thinking and revenue companies are implemented in the business models of modern libraries.

Aarhus Library is a pioneer in innovative thinking. Therefore, it has teamed up with Chicago Public Library in order to take it to the next step. Together with Chicago Public Library, Aarhus Library gets funding to develop a generic innovation model, which should be used by libraries all over the world. Conferences are held on "forward-thinking library professionals, innovators and decision-makers who are pushing boundaries and making changes that support learning in the 21st century" (nextlibrary.net). In other words, it is not only in Aarhus they have discovered the need for a new business model in libraries, and together, professionals are trying to figure out how to run libraries in the future. Nextlibrary.net also states that the conference will "look ahead and explore the continuously evolving nature of the public library." This collaboration between Aarhus and Chicago Libraries has, as mentioned, also been awarded a grant from the Gates Foundation, which is to be used to "create a new model for innovation, experimentation and decisionmaking within libraries” (libraryjournal.com). Library Journal gives Aarhus the following credit as well:

“The Aarhus Library is known for its innovations as well, including work on open data, a garden partnership, designing a children's library of the future, gaming, maker and hacker spaces, a transformation lab, projects for improving external partnerships and involving users, and a project for bringing digital resources into the physical space of the library through installations."

\subsection{Communication and open business modeling}

As stated in the theory section, open business modeling is a way of creating a competitive business model through corporation with external partners, both companies and by customer-integration. This section will analyses how the library of Aarhus is using this modeling to create a valuable business model both through partnerships and working together with the citizens.

\subsubsection{Partnerships}

Aarhus Library is also cooperating with Danish companies. These projects are on a lower level relative to the Chicago Public Library-project, because they are more directly related to the customers and within innovative user-IT. Together with The Alexandria institute they have created a transformation lab, which is a new vision for the future physical library (aakb.dk). As respondent 1 states:

“... The last couple of years a large area has been used for what we call the transformation lab. This is a place where we create new things together with The Alexandria institute..."

The purpose of the transformation lab is to create a flexible physical framework for different interactive projects (aakb.dk). A project like that described here:

...we made info galleries, which are a big-screen tool, a kind of program that controls the big-screens that can both create interaction, motion sensors and be used for presenting stuff that is individually edited. We developed this tool together with ISIS Katrinebjerg...

The info galleries are an example on a transformation lab project. ISIS Katrinebjerg is under administration of The Alexandria institute and is creating interactive user-media. The quote shows how the library is working together with external companies in order to develop media that can attract new users to the library. The benefits of these different partnerships are the ability address weaknesses in the own organization. Aarhus Library does not have the competences to develop IT-solutions, so they join forces with a company like The Alexandria institute. Then Aarhus Library can focus on providing great service and developing new concepts. The alliance with the Chicago Public Library is more like an exploitation of re-sources in creating a model that both can benefit from for half the price. This includes the different competences they have created based on the culture changes and way of running a library.

\subsubsection{Customer-integration}

Because of the diverse customer base the new Urban Media Space is com-mitted to satisfy, the participation from citizens is an important factor. The Media Space is developed through the vision that citizen-participation should be the core in order for the space to last for the next 100 years (Aarhusmodel for borgerindragelse, 2004). This is important because it is almost impossible to satisfy all segments. By asking and cooperating with the citizens, the staff can create offers that are tailored to different segments. A good example of the customer participation is captured in this quotation: 
“... We had a funny coincident at the library of Tranbjerg, were some women started showing up (...) they were sitting and knitting. Then at one point, one of our staff members asked them if they were interested in making a small exhibit about what they were doing. In this way, a small knitting club has been organized where they tell stories and invite people to join ..."

This is an example on how actors with different topoi can use the factual possibilities of a library. It places a demand on the staff to be quick to catch an idea and involve the citizens in an active way. The library has to be adaptive and flexible in their daily work.

Another way to participate with the customers is by visiting them at their homes and observing how they use media in their private surroundings. Such a project has been managed in corporation with AIDO, which is a large design agency. They have trained the staff of Aarhus Library in what respondent 1 calls design thinking with a human approach. The staff is observing the use of I-Pads, what books are present at the shelves and are they even reading books. Afterwards, employees analyze the information gathered and generate ideas through brainstorming, in this way creating services tailored for the citizens based upon their own experiences (interview, respondent 1).

The benefits of having this close customer-integration is that the library is able to create offers that are developed based on customer demands. This can both attract new users and retain existing users. Especially attracting the younger segments can be difficult with the alternative possibilities interactive online media offer today. Then by asking them, the library can catch up on the latest trends and create offers that are more attractive.

We argue that the business model of Aarhus Library situated between a type 5 and a type 6 business model (Chesbrough 2007). This is due to the adaptive approach to customers and initiatives. Another reason is the close corporation with different companies. Both the library and technology companies have made it possible to start up smaller projects that address the competences the library lacks. They have built a close partnership with both customers and interest companies, and created a proactive business model. It can be difficult to decide upon the exact business model type since the different types of business models described by Henry Chesbrough are aimed at production companies. Nonetheless the framework presented seemed suitable for the case.

\subsection{Justification of existence}

Under the assumption that public libraries are closing, visitor numbers decreasing and the world digitalizing and everything ever written can be found on the Internet, what do we need libraries for? First of all - and as already mentioned - the law states that libraries have an obligation to promote information, education, and cultural activities. Libraries are rather transformed into citizen centers, meaning that libraries have accepted the fact that physical media is losing relevance. Instead, the library is used for clubs, homework cafés, volunteering, and citizen service centers. This development makes respondent 1 confident that libraries have a future. He states that:

\section{"There is a social wish and need for these neutral physical meeting locations."}

Furthermore there is no clear answer to the assumption that visitor numbers are dropping. Danish statistics show that in Aarhus, visitor numbers are decreasing. But the overall numbers for Denmark show the opposite. In addition, actors borrow fewer media from the library each year. The digitization is unavoidable, but as respondent 1 also states: "We are stealing with arms and legs," meaning, the libraries take advantage of the digital development and the new ideas from other distributors. As they do not see themselves being in competition with anyone, they do not feel threatened by the development either. This situation is different for the state libraries. Obviously they experience the digitization too, and according to respondent 2, it is a challenge. Yet, one of their main tasks is to work as storage for the public libraries. Where the public libraries throw out their physical media, the state library has to keep a copy of everything, and they then lend out to the public libraries (second interview). Just that point can justify the existence for state libraries - there is a cultural interest in preserving physical media, and as long as public libraries can justify their existence, so can the state libraries.

Furthermore, there is a need for a library for university students. Obviously, the physical space is needed for studying, but media from the state library is also necessary. In addition, physical media have advantages which technology cannot compete against yet:

“... you can have 2-3 books lying next to each other and look something up in them at the same time. There are still some things our digital gadgets cannot deal with quit as well.”

As respondent 2 also states: 
"...We are actually a pretty well visited library. If you calculate the visiting hours per square meters, we might be the most visited place in Denmark. We had 425.000 visitors in 2013. That is a lot, because if you look at the average time of a visit it is above three hours..."

So this particular library has a lot of visitors, which justifies the existence. But we need to separate this kind of library (state library) from the public libraries, which do not have a new set of students each year.

\section{Discussion}

The purpose of the paper was to investigate how the business model of future libraries would look like. The findings have shown that libraries in the future have to be very adaptable to changes. They need to catch upcoming trends with both internal innovations, from external users, and in cooperation with other libraries. This section will discuss the limitations of the paper, the implications the study has for other libraries, and preview what future research could include.

\subsection{Limitations}

This article focuses only on public libraries for citizens but compares findings with state libraries affiliated with Aarhus University in order to support the arguments. The views in the empirical data are collected only from library representatives. Due to our methodology, there is some subjectivity both from the respondents and the authors. We acknowledge other views, but we find the chosen approach suitable for the article. This article could have benefitted from interviews with the users of the libraries, in order to get more perspective on the case. This has not been done, both because of the scope and timeframe of the article but also because respondent 1) states there is no specific target group, and therefore it would be a too extensive process to collect the data.

\subsection{Implications for other libraries}

Our findings have a couple of implications for other libraries. In order for libraries to attract users in the future, they need to be innovative and trendy. For this, innovative topos to shine through and create results for the libraries and not just be a strategic term used among the management, every employee must be prepared and willing to adapt to the reformed business model. Because of this, the libraries will have to not only increase the focus on the actors that use the libraries but also on the actors they have working there. Basically, the human resource aspect of the organizations will have to be taken to the strategic level we see in larger organizations.

These demands for innovation and adaptability put a high pressure on the budget. The library of Aarhus has received rather large amounts of funding so that they are capable of developing a flexible business model. But the smaller libraries in the outskirts of Denmark do not get the same exposure and have more difficulty in attracting funds. This means they are very dependent on public funding while the pressure on the municipalities is getting bigger and they are cutting the budgets (db.dk) where possible. This has the consequence that the small libraries can be negatively affected. But if they are able to show an innovative and sustainable business model, then they may be able to justify their existence and raise the necessary amount of money.

The new business model of Aarhus Library can also be a benefit for the smaller, less exposed libraries. They can simply be inspired by the initiatives Aarhus Library takes, by first observing what is popular and what is not among users and then avoid making the pertinent mistakes.

\subsection{Further research}

It was stated in the limitations that the empirical data only contain the view of the library. It could be interesting to include the customer perspective. What do the citizens expect from a modern library? What will attract them to use the library on a regular basis?

\section{Conclusion}

Different elements need to be taken into account when defining a business model for public libraries. These elements are customer integration, innovation, and broad collaboration in order to satisfy the diverse customers' demands. Due to our pragmatic constructivist approach, we wished to conduct a generic business model, but our case study has shown that the future business models of public libraries cannot be defined specifically. But we can say that it focuses on the above mentioned elements as well as on being adaptive to a changing environment; a change in reading habits, requests for more and easier accessible services, and various offers for all citizens. 


\section{References}

Bock, A. J., Opsahl, T., George, G., \& Gann, D. M. 2012. The effects of culture and structure on strategic flexibility during business model innovation. Journal of Management Studies, 49(2): 279-305.

Casadesus-Masanell, R., \& Zhu, F. 2013. Business model innovation and competitive imitation: the case of sponsor-based business models. Strategic Management Journal, 34(4): 464-482.

Chad, K., \& Miller, P. 2005. Do Libraries Matter? The Rise of Library 2.0. White PaperTalis Company; http://www.talis.com/applications/downloads/white_papers/DoLibrariesMatter.pdf.

Chesbrough, H. 2007. Business model innovation: it's not just about technology anymore. Strategy \& Leadership, 35(6): 12-17.

Chesbrough, H. 2010. Business model innovation: opportunities and barriers. Long Range Planning, 43(2-3): 354-363.

Chesbrough, H. 2012. Open innovation: where we've been and where we're going. Research-Technology Management, 55(4): 20-27.

Chesbrough, H., \& Schwartz, K. 2007. Innovating business models with co-development partnerships. ResearchTechnology Management, 50(1): 55-59.

Dalby, J., Nielsen, L. S., Lueg, R., Pedersen, L., \& Tomoni, A. C. 2014. National culture and business model change: a framework for successful expansions. Journal of Enterprising Culture: forthcoming.

Eriksson, P., \& Kovalainen, A. 2008. Qualitative Methods in Business Research. Thousand Oaks, CA: Sage.

Haubro, A. P., Lomholt, H. A., Lueg, R., Nielsen, S. V., \& Knudsen., U. 2015. Tactical and strategic choices in business models: evidence from a Danish fashion outlet. Journal of Fashion Marketing and Management: forthcoming.

Jakobsen, M., Johanson, I.-L., \& Nørreklit, H. (Eds.). 2011. An Actor's Approach to Management: Conceptual Framework and Company Practices. Copenhagen: DJØF.

Larsen, M. K., Lueg, R., Nissen, J. L., Schmaltz, C., \& Thorhauge, J. R. 2014. Can the business model of Handelsbanken be an archetype for small and medium sized banks? A comparative case study. Journal of Applied Business Research, 30(3): 869-882.

Lueg, R., Clemmensen, S. N., \& Pedersen, M. M. 2013a. The role of corporate sustainability in a low-cost business model - A case study in the Scandinavian fashion industry Business Strategy and the Environment (forthcoming).

Lueg, R., Malinauskaite, L., \& Marinova, I. 2014. The vital role of business processes for a business model: the case of a startup company. Problems and Perspectives in Management, 12(4): 213-220.

Lueg, R., Nedergaard, L., \& Svendgaard, S. 2013b. The use of intellectual capital as a competitive tool: a Danish case study. International Journal of Management, 30(2): 217-231.

Malmmose, M., Lueg, R., Khusainova, S., Iversen, P. S., \& Panti, S. B. 2014. Charging customers or making profit? Business model change in the software industry. Journal of Business Models, 2(1): 19-32.

Morris, M., Schindehutte, M., \& Allen, J. 2005. The entrepreneur's business model: toward a unified perspective. Journal of Business Research, 58(6): 726-735.

Oke, A. 2004. Barriers to innovation management in service companies. Journal of Change Management, 4(1): 31-44.

Pateli, A. G., \& Giaglis, G. M. 2005. Technology innovation-induced business model change: a contingency approach. Journal of Organizational Change Management, 18(2): 167-183.

Plé, L., Lecocq, X., \& Angot, J. 2010. Customer-integrated business models: a theoretical framework. M@n@gement, 13(4): 226-265.

Sosna, M., Trevinyo-Rodríguez, R. N., \& Velamuri, S. R. 2010. Business model innovation through trial-and-error learning: the Naturhouse case. Long Range Planning, 43(2): 383-407.

Yin, R. K. 2014. Case Study Research: Design and Methods (5th ed.). Los Angeles, CA: Sage. 


\section{Webpages}

https://www.aakb.dk/blog/transformation-lab-prototyping-the-future [Accessed 28. April 2014]

https://www.aakb.dk/in-english [Accessed 18. May 2014]

http://www.aakb.bib.dk/nythb/html/arealforhold.htm [Accessed 13. April 2014]

http://www.b.dk/danmark/bibliotekerne-rammes-af-en-boelge-af-lukninger [Accessed 13. May 2014]

http://lj.libraryjournal.com/2013/07/shows-events/ala/1-million-gates-grant-to-fund-chicago-aarhus-librariesinnovation-partnership-ala-annual-2013/\# [Accessed 13. April 2014]

http://www.nextlibrary.net/ [Accessed 13. April 2014]

http://www.urbanmediaspace.dk/en/project/facts [Accessed 13. April 2014]

http://www.realdania.dk/filantropiske-programmer/samlet-projektliste/urban-mediaspace-aarhus [Accessed 12. May 2014]

http://www.db.dk/kalender/workshop-\%C3\%A6rlig-dialog-om-den-n\%C3\%B8dvendige-innovation-i-bibliotekerne 